\title{
Validity of Partial Protocols to Assess the Prevalence of Periodontal Outcomes and Associated Sociodemographic and Behavior Factors in Adolescents and Young Adults
}

\author{
Marco A. Peres ${ }^{\star}$, Karen G. Peres ${ }^{\star}$, Andreia M. Cascaes ${ }^{\dagger}$, Marcos B. Correa ${ }^{\ddagger}$, Flávio F. \\ Demarco $^{\dagger} \neq$, Pedro C. Hallal ${ }^{\dagger}$, Bernardo L. Horta ${ }^{\dagger}$, Denise P. Gigante ${ }^{\dagger}$, and Ana B. Menezes ${ }^{\dagger}$ \\ *Research Group in Oral Epidemiology and Public Health Dentistry, Postgraduate Program in \\ Public Health, Federal University of Santa Catarina, Florianópolis, Santa Catarina, Brazil \\ †Postgraduate Program in Epidemiology, Federal University of Pelotas, Pelotas, Rio Grande do \\ Sul, Brazil \\ ‡Postgraduate Program in Dentistry, Federal University of Pelotas
}

\section{Abstract}

\begin{abstract}
Background-Most studies comparing prevalence of periodontal disease and risk factors by using partial protocols were performed in adult populations, with several studies being conducted in clinical settings. The aim of this study is to assess the accuracy of partial protocols in estimating the prevalence of periodontal outcomes in adolescents and young adults from two populationbased birth cohorts from Pelotas, Brazil, and to assess differences in the estimation and strength of the effect measures when partial protocols are adopted compared to full-mouth examination.
\end{abstract}

Methods-Gingival bleeding at probing among adolescents $(n=339)$ and young adults $(n=720)$ and dental calculus and periodontal probing depth among young adults were assessed using fullmouth examinations and four partial protocols: Ramfjord teeth (RT), community periodontal index (CPI), and two random diagonal quadrants (1 and 3, 2 and 4). Socioeconomic, demographic, and periodontal health-related variables were also collected. Sensitivity, absolute and relative bias, and inflation factors were calculated. Prevalence ratio for each periodontal outcome for the risk factors was estimated.

Results-Two diagonal quadrants showed better accuracy; RT had the worst, whereas CPI presented an intermediate pattern when compared to full-mouth examination. For bleeding assessment in adolescence, RT and CPI underestimated by $18.4 \%$ and $16.2 \%$, respectively, the true outcome prevalence, whereas among young adults, all partial protocols underestimated the prevalence. All partial protocols presented similar magnitude of association measures for all investigated periodontal potential risk factors.

Conclusion-Two diagonal quadrants protocol may be effective in identifying the risk factors for the most relevant periodontal outcomes in adolescence and in young adulthood.

\section{Keywords}

Data collection; epidemiologic studies; periodontal index

Correspondence: Marco A. Peres, Universidade Federal de Santa Catarina, Centro de Ciências da Saúde, Departamento de Saúde Pública, Campus Universitário Trindade, Florianópolis, Santa Catarina, Brazil, 88010-970. mperes@ccs.ufsc.br..

The authors report no conflicts of interest related to this study. 
Epidemiologic studies of periodontal diseases present inherent difficulty concerning a plethora of case definitions and operational aspects, such as cost, time constraints, and exam protocol accuracy. A systematic review of the definition and the methods of periodontitis concluded that epidemiologic studies of periodontal diseases are complicated by the diversity of methodologies and definitions used. ${ }^{1}$

However, the usual clinical norm for a full-mouth examination (FM), the "gold standard" for clinical assessment of periodontal disease, ${ }^{2}$ involves the examination of six sites on all existing teeth, involving up to 168 sites per mouth (excluding third molars). FM may not be feasible in some epidemiologic studies because it significantly increases the examination time. ${ }^{3}$ Considering that periodontal diseases exhibit bilateral symmetry, partial record protocols, defined as the clinical assessments on a "representative set" of teeth or sites within the patient, ${ }^{4}$ have been alternatively used. Several partial protocols have been proposed, such as the Ramfjord teeth (RT), ${ }^{5}$ the community periodontal index (CPI), ${ }^{6}$ and two random quadrants, ${ }^{7}$ among others. All of them have operational benefits along with some limitations, mainly the underestimation of the "true" prevalence of the diseases under investigation. ${ }^{8}$

Large health surveys that include periodontal assessment, such as the National Health and Nutrition Examination Survey (NHANES), are performed periodically and have provided important information both to surveillance of the disease and in terms of periodontal risk factors. However, Eke et al. ${ }^{8}$ found that partial protocols, two random quadrants such as used in NHANES, underestimated the prevalence of periodontal disease by $50 \%$, which led Albandar ${ }^{9}$ to propose an inflation factor to correct this underestimation and then allow the use of data provided by NHANES to estimate the prevalence of periodontal diseases.

In addition to the need for an accurate estimation of the prevalence of periodontal diseases from population-based health surveys, it is also necessary to identify the strength of association of different partial protocols when compared to FM when analytic epidemiologic studies are undertaken. Thomson and Williams ${ }^{10}$ addressed this issue comparing the use of FM and partial records (two quadrants) to measure the prevalence of different periodontal outcomes and also calculated the magnitude of effect measures of periodontal risk factors. They found an underestimation of the prevalence of gingival recessions when they adopted a partial protocol. Moreover, they found different odds ratios for the association between periodontal disease and smoking status or patterns of dental visits. This means that, in addition to underestimating the prevalence, the use of partial protocol may bias effect measures, which are of concern to analytic studies.

Most studies comparing prevalence of periodontal disease and risk factors by using partial protocols were performed in adult populations from high-income countries, with several studies being conducted in clinical settings. There is a lack of studies addressing this issue among adolescents or young adults in low- and middle-income countries. This is of concern because the accuracy of a disease assessment depends on the prevalence level of the disease when surveys are undertaken as well as of the population risk factor exposure levels, ${ }^{11}$ which vary across different countries. ${ }^{12-15}$

This study aims to answer the following research questions: 1) How accurate are partial protocols to estimate prevalence of periodontal outcomes in adolescents and young adults from Brazil? 2) Are there differences in the estimation and strength of the effect measures when partial protocols are adopted compared to FM? 


\section{MATERIALS AND METHODS}

Oral health studies (OHS) were performed nested to the 1982 and 1993 Pelotas, Brazil, population-based birth cohort studies. Pelotas is a city with 327,778 inhabitants located in the extreme south of Brazil, close to the border with Uruguay. The economy of the city is based on livestock farming, agriculture, and commerce, but Pelotas is also a university center. ${ }^{16}$

\section{Pelotas Birth Cohort}

In 1982, all hospital deliveries that occurred in the city were identified, and the 5,914 children from mothers living in the urban area of the city were included in the study. The children were weighed and measured, and their mothers were interviewed. This cohort has been followed up several times since then. A detailed explanation about methodologic procedures has been described previously. ${ }^{17}$

In 1997, when all cohort participants reached 15 years of age, we randomly selected 900 cohort participants for a follow-up visit, of whom 888 (98.7\%) took part in the first oral health study (OHS-97). In the OHS-97, we did not analyze periodontal diseases. All of the 888 participants were contacted again in 2006, when they were 24 years old, and were invited to participate in the second oral health study (OHS-06). Data collection included dental examination and a questionnaire. Dental examination was performed to assess several dental outcomes, such as dental caries, soft-tissue lesions, gingival bleeding, dental calculus, and periodontal probing depth (PD). ${ }^{18}$ The fieldwork team comprised six dentists (MBC; Felipe Senh, private practice, Pelotas, Brazil; Leticia Kornalevski, Brazilian Public Health System, Chuvisca, Brazil; Carla Albino, Brazilian Health System, Santa Cruz do Sul, Brazil; Jose Marimon and Diogo Antunes, private practices, Pelotas, RS, Brazil) and four advanced dental students (Otávio Dávila, Federal University of Rio Grande do Sul, Brazil; and Gregori Boeira, Sandrina Henh, and Maria Beatriz Junqueira, Federal University of Pelotas), who each examined and interviewed similar numbers of participants.

\section{Pelotas Birth Cohort}

The OHS started in December 1998, the year when the children were 5 years old, as a crosssectional study nested in the birth cohort. In the perinatal study $(\mathrm{N}=5,249)$, all the five hospitals in Pelotas were visited twice daily by a team of medical students from January 1 to December 31, 1993. The adolescents identified accounted for $99 \%$ of the babies born to mothers living in the urban area of the city. In 1998, a sample of the original cohort, consisting of all low-birth-weight adolescents plus a random $20 \%$ of the remainder, was revisited. Of 1,460 eligible adolescents, 1,270 were located. A subsample $(n=400)$ drawn from this group was examined to estimate the prevalence of dental caries and malocclusion (OHS-99). Because low-birth-weight adolescents were over-represented in the oral study sample (29.7\% when compared to $10 \%$ in the original cohort), all analyses were weighted. The response rate was 359 adolescents. Non-responses were mainly because of families having moved out of the city. ${ }^{19}$

All the 359 adolescents who participated in the OHS-99 were again visited in their homes in 2005 when they were 12 years old. The response rate was $94.4 \%(n=339)$. A structured interview, including questions about use of dental services, dental pain, and oral behaviors (toothbrushing, flossing, use of topical fluorides) was applied. In addition, a short version of the Oral Impacts on Daily Performance questionnaire ${ }^{20}$ was also administered. The dental exams included fluorosis diagnosis, ${ }^{21}$ dental trauma ${ }^{22}$ and associated treatment needs, dental caries, ${ }^{21}$ malocclusion, ${ }^{21}$ and gingival bleeding on probing (BOP).${ }^{21}$ Artificial lights were 
used to improve visualization. Four teams were formed, each consisting of an examiner and an interviewer.

\section{Periodontal Outcomes: FM}

We assessed gingival BOP (12 years of age, OHS-99; 24 years of age, OHS-06), dental calculus, and periodontal pocket (24 years of age, OHS-06). For the gingival assessments, at ages 12 and 24 years, and calculus and periodontal pocket at 24 years, dental examination was performed at six sites in each presented tooth (mesio-buccal, mid-buccal, disto-buccal, disto-lingual, mid-lingual, and mesio-lingual) using a ball-ended periodontal probe. Gingival bleeding and calculus were also recorded (as "present" or "absent"). Periodontal PD was measured as the distance (in millimeters) from the free gingival margin to the base of the gingival crevice by using depth classification as follows: from 0 to $3 \mathrm{~mm}$ was recorded as an absence of periodontal pocket, from 4 to $5 \mathrm{~mm}$ was registered as a shallow periodontal pocket, and a pocket $\succeq 6 \mathrm{~mm}$ was recorded as a deep periodontal pocket. ${ }^{21}$

Examiner reliability was assessed by means of weighted $\kappa$ for categoric variables. The lowest value was 0.6 for gingival bleeding, whereas the majority of values were 1.0.

\section{Partial Protocols}

After the FM had been performed, a dataset was created. From the same dataset, we simulated four different partial protocols. This option was chosen because ethical concerns precluded five different examinations (FM and four partial protocols).

We estimated four different partial protocols among those more often used in epidemiologic studies of periodontal diseases: RT, CPI, and two random diagonal quadrants ( 1 and 3, 2 and 4). RT uses teeth \#3, \#8, \#12, \#19, \#24, and \#28; CPI uses teeth \#2, \#3, \#8, \#14, \#15, \#18, $\# 19$, \#24, and \#30; and two random quadrant protocols use examination of all teeth in the random quadrants, i.e., 1 and 3, 2 and 4. The number of sites analyzed for each assessment of partial protocol was the same six used in FM. ${ }^{4}$

\section{Explanatory Variables}

A face-to-face questionnaire was administered to assess socioeconomic, demographic, toothbrushing habits, dental visit, and smoking variables. Socioeconomic and demographic variables were recorded as follows: 1) sex of participant; 2) self-reported skin color indicated according to Brazilian census categories (white, light-skinned black, dark-skinned black, yellow-Asian descendants, and indigenous; however, the categories yellow-Asian descendants and indigenous were excluded due to the very low frequency in the sample); 3) per capita family income in reais per month ( $R$ \$, Brazilian currency) at the time of participants' birth was obtained by dividing the family income (continuous variable) by the number of inhabitants per household, and then categorized according to the number of Brazilian minimum wage (BMW) per month as $\unlhd, 1.1$ to 3 , and 23.1 (in 2006, 1 BMW was equivalent to US \$200.00); 4) maternal schooling at participants' birth was categorized according to the number of years of study ( $\geq 12,9$ to 11,5 to 8 , and $\leq 4$ ).

Toothbrushing habits, dental visit, and smoking were recorded as follows: 1) How many times a day do you toothbrush?; 2) Did you have a dental appointment in the past 12 months? (yes or no); and 3) Have you smoked $\geq 1$ cigarette in the past 30 days? (yes or no; smoking at 12 years was not collected).

\section{Statistical Analyses}

Data were analyzed with statistical software. ${ }^{\S}$ The prevalence of all periodontal outcomes investigated gingival bleeding for 12 and 24 years of age, and dental calculus and 
periodontal pockets for each protocol were calculated. The RT, CPI, half-mouth quadrants 1 and 3, and half-mouth quadrants 2 and 4 were compared to the FM used here as the gold standard, allowing the assessment of the following: 1) sensitivity (prevalence in tested protocol/true prevalence according to $\mathrm{FM} \times 100$ ); 2) absolute bias (absolute difference between prevalence equals prevalence in the tested protocol minus true prevalence according to $\mathrm{FM}$ ); 3) relative bias (percentage of underestimation of true prevalence equals absolute difference/true prevalence according to $\mathrm{FM} \times 100$ ); and 4) inflation factor (true prevalence according to FM/prevalence in the tested protocol). ${ }^{8}$ Finally, we estimated the prevalence ratio (PR) of each periodontal outcome for the risk factors using Poisson regression analyses ${ }^{23}$ with robust adjustment of the variance.

\section{RESULTS}

The response rate was $94.4 \%$ in the 1993 Pelotas birth cohort at 12-year-old OHS ( $\mathrm{n}=339$ adolescents) and $81.1 \%$ in the 1982 Pelotas birth cohort study at 24-year-old OHS ( $\mathrm{n}=720$ adults). At 12 years old, $1.5 \%$ of adolescents presented $\geq 1$ tooth loss (mean: $0.02 ; \mathrm{SD} \pm 1.8$ ), and at 24 years old, tooth loss achieved was $47.2 \%$ (mean: $0.98 ; \mathrm{SD} \pm 1.4$ ) of the studied sample (data not shown).

Table 1 presents a description of sociodemographic characteristics, daily toothbrushing habits, use of dental services, and smoking in those among the sampled population who completed the questionnaire. In both studies, male participation was slightly higher than female. In relation to skin color, most of the participants were white in both studies. The percentage of patients who visited a dentist in the previous year was higher among adults (55.6\%) than among adolescents (35.0\%). The proportion of mothers with low education level was higher in the 1982 birth cohort (32.3\%) when compared to the 1993 birth cohort $(28.3 \%)$. Approximately $25 \%$ of 24 -year-old participants were smokers.

The prevalence of periodontal diseases at 12 and 24 years according to different protocols are presented in Table 2. Under the gold-standard protocol, the prevalence of BOP in adolescents was much higher than in adults. The prevalence of dental calculus and periodontal pockets were $87.4 \%$ (95\% confidence interval [CI], 84.7 to 89.7 ) and $3.3 \%$ (95\% CI, 2.1 to 4.9), respectively, according to FM. At 12 years, among the protocols tested, the lowest prevalence of BOP was found in the RT protocol and the highest in the halfmouth protocol for quadrants 1 and 3. In adults, the lowest prevalenceof BOP was achieved with the RT protocol and the highest with the half-mouth protocol for quadrants 2 and 4 . In relation to dental calculus, a different prevalence was found only between the gold standard and the RT protocol. The same situation occurred with periodontal pockets: lower prevalence was found with RT protocol when compared to FM.

Table 3 presents the sensitivity, absolute bias, relative bias, and inflation factor of different protocols compared to the gold standard. There was a high sensitivity (>80\%) for bleeding at 12 years. However, the RT protocol showed the largest error: the true prevalence of this condition was underestimated in $18.4 \%$. Bleeding at 24 years, according to RT protocol, showed low sensitivity, whereas for the other protocols, the sensitivity ranged from $74.8 \%$ (95\% CI, 69.2 to 79.9 ) for the CPI to $79.6 \%$ (95\% CI, 74.3 to 84.3) for the half-mouth quadrants 2 and 4 . The RT protocol underestimated in $43.5 \%$ the true prevalence of this condition, which is approximately twice that observed in other tested protocols. A high sensitivity, ranging from $92.7 \%$ to $96.8 \%$, was observed for the dental calculus prevalence estimation. The smallest error for this condition was obtained in the CPI protocol, with $1.5 \%$ of real prevalence underestimation and highest with RT protocol that presented $7.3 \%$ of

\footnotetext{
$\S_{\text {Stata 11.0, StataCorp, College Station, TX }}$
} 
underestimation. The lowest sensitivities were observed for periodontal pocket status. Once again, the RT protocol presented the worst performance, underestimating $\approx 70 \%$ of the real prevalence. The inflation factor of this condition ranged from 1.38 (half-mouth protocol quadrants 1 and 3) to 3.30 (RT).

Table 4 shows PR for gingival bleeding according to independent variables assessed by different protocols for adolescents and adults. In general, for gingival bleeding in 12 and 24 year olds, there was similarity in the estimation of PR according to different protocols. However, some statistical differences were found. In adolescents, only the CPI protocol identified higher prevalence of bleeding in dark-skinned blacks; in adults, only half-mouth protocol 2 and 4 quadrants identified a higher prevalence for lighter-skinned blacks. When analyzing income and education, RT protocol and half-mouth protocol quadrants 1 and 3 differed only in one category of mother's schooling ( $\geq 12$ years of study), and, for family income, we observed difference with RT (category 1.1 to 3 BMW) and CPI (category $\geq 3$ BMW) protocols.

PRs for dental calculus and PD in adult patients are shown in Table 5. Similar to gingival bleeding, some differences were found for skin color, mother's education, and family income. For dental calculus, the only difference was found with RT protocol in lighterskinned blacks. PD presented statistical difference between mother's schooling (category 5 to 8 years) with CPI and half-mouth protocol quadrants 2 and 4 ; for income, we found difference only in the category 1.1 to $3 \mathrm{BMW}$ for both half-mouth protocols.

\section{DISCUSSION}

The main findings of this study indicate that, in general, two diagonal quadrants showed better accuracy, RT had the worst accuracy, and CPI presented an intermediate pattern when compared to FM. For bleeding assessment in adolescents, RT and CPI underestimated by $18.4 \%$ and $16.2 \%$, respectively, the true outcome prevalence, whereas among young adults, all partial protocols underestimated the prevalence when compared to FM. These findings have important implications for the estimation of periodontal conditions on national surveys conducted according to these protocols. It is noticeable that the prevalence of gingival bleeding was $80 \%$ among adolescents and $\approx 30 \%$ among adults. For dental calculus and periodontal pockets, only RT protocol biases prevalence estimates, whereas for periodontal pocket assessment, all partial protocols showed low sensitivity. However, periodontal pockets had a very low prevalence. Contrary to the common belief that sensitivity and specificity are fixed properties of the test itself (partial protocols in this case), regardless of the characteristics of the study population, these properties depend on the prevalence of the condition under study. ${ }^{24}$ This is particularly true for conditions based on a continuous scale that is more or less arbitrarily changed into a binary variable, as is the case of the periodontal pocket. For continuous trait, the probability of misclassifying a true positive as a negative tends to be higher for individuals whose true values are near the chosen cutoff value (such as periodontal disease). Thus, the sensitivity and specificity of a given definition of a condition does depend on the distribution of the severity on the condition, ${ }^{24}$ which was not assessed in our study.

The underestimation of true prevalence of most common periodontal outcomes corroborated previous studies undertaken among older adults. ${ }^{8-10}$ This is of concern because international agencies, such as the World Health Organization, recommended the use of the CPI, a partial protocol, to assess both prevalence and extension of periodontal diseases at population level. ${ }^{21}$ However, for analytic studies, we noticed that all protocols presented similar magnitude of association measures for all investigated periodontal outcome potential risk factors when unadjusted analyses were performed. Similar to previous studies, ${ }^{2,10}$ we found 
modest differences in the PR estimates of risk factors. Therefore, partial protocols are acceptable for use when analytic epidemiologic studies are undertaken. Partial protocols gather sufficient information to measure the association of periodontal diseases and sociodemographic and behavior factors among adolescents and young adults. However, this pattern would be different for an older population or a young population with higher levels of risk factors and/or periodontal diseases. This is an important finding once Dowsett et al. ${ }^{2}$ estimated that FM of six sites per tooth to assess periodontal pockets and clinical attachment loss (AL) performed by experienced periodontologists takes 17 minutes compared to 8.5 minutes when half-mouth protocols are used. Time, cost, participant's discomfort, and examiner fatigue may be significantly reduced by using half-mouth protocols. Therefore, along with efficiency, ethical concerns may reinforce the use of partial protocols in large epidemiologic studies. It is important to highlight that this recommendation may not be done for longitudinal studies, in which site-specific incidence is one aim to be reached.

The similarity of the dental caries distribution in both the left and right sides of the mouth is very well known. ${ }^{25-28}$ Nevertheless, regarding periodontal outcomes, this pattern is not easily identifiable because some periodontal outcomes, such as gingival recession and gingival bleeding, rely on the effectiveness and power of mechanical toothbrushing, which differ between a right- and left-handed person. For example, for a right-handed person, the prevalence of gingival recession is more prevalent on the left side of the mouth. ${ }^{10} \mathrm{In}$ contrast, our findings indicated a very similar prevalence pattern of periodontal outcomes when two diagonal protocols were used ( 1 and 3 versus 2 and 4$)$. This lack of difference may be attributable to the relatively young population under investigation and because we did not assess gingival recession.

\section{Strengths and Weaknesses}

Our studies used data from two large samples of population-based birth cohort studies and had high examiner reliability, and the examiners were masked to the main research questions. We are unaware of any study comparing the use of different protocols to assess prevalence of periodontal outcomes and their associated factors in adolescence and young adulthood in home-based settings.

Conversely, we measured periodontal pockets using a categoric scale and not a continuous one; we did not collect gingival recession or clinical AL, more severe cases of periodontal diseases were infrequent, and we used tobacco status as a binary variable. In addition, our analysis focused on the prevalence estimation and the assessment of the association measurement between periodontal outcomes and potential risk factors. The extension and severity of the periodontal outcomes were not taken into consideration in this work. The use of several measures of different dental outcomes is not always possible in multidisciplinary cohort studies because of logical and ethical reasons. The Pelotas studies have a very busy assessment protocol followed by cohort members, which means that there is no time for more detailed dental examination. ${ }^{17}$

\section{CONCLUSIONS}

In summary, we conclude that some partial protocols, such as two diagonal quadrants, may be useful and effective in identifying potential risk factors for most relevant periodontal outcomes in adolescence and in young adulthood. Conversely, partial protocols may underestimate the true prevalence of periodontal outcomes, and their validity depends on the population age. This is particularly more valid among adolescents and younger adults than in older adults because the number of sites to be examined in the former is much higher than that in the latter as a result of the high rates of tooth loss; however, there is a lower level of disease to be detected in younger individuals. Definitely, periodontal diseases are not a 
major problem in adolescents and young adults. However, because we intend to follow up these two birth cohorts until adulthood, the assessment of early stages of periodontal diseases is useful to improve our understanding of its development.

\section{Acknowledgments}

The 1982 Pelotas birth cohort was supported by the Wellcome Trust (London, UK) initiative "Major Awards for Latin America on Health Consequences of Population Change." Earlier phases of the 1982 cohort study were funded by the International Development Research Center (Canada); the World Health Organization (Department of Child and Adolescent Health and Development, and Human Reproduction Programme, Geneva, Switzerland); the Overseas Development Administration (UK); the United Nations Development Fund for Women; the National Program for Centres of Excellence (Brazil); the Brazilian National Council for Scientific and Technological Development (CNPq [Conselho Nacional de Desen-volvimento Científico e Tecnológico], Brazil); and the Ministry of Health (Brazil). The oral health study was supported by CNPq Grant 47698520045. The 1993 Pelotas birth cohort was supported by the Wellcome Trust. The initial phases of the cohort study were financed by the European Union (Brussels, Belgium), PRONEX (Programa de Apoio a Núcleos de Excelência, Brazil), CNPq, and the Brazilian Ministry of Health. The oral health study was sponsored by CNPq Grant 403362/2004-0.

\section{REFERENCES}

1. Savage A, Eaton KA, Moles DR, Needleman I. A systematic review of definitions of periodontitis and methods that have been used to identify this disease. J Clin Periodontol. 2009; 36:458-467. [PubMed: 19508246]

2. Dowsett SA, Eckert GJ, Kowolik MJ. The applicability of half-mouth examination to periodontal disease assessment in untreated adult populations. J Periodontol. 2002; 73:975-981. [PubMed: 12296597]

3. Vettore MV, Lamarca G, de A, Leão AT, Sheiham A, Leal Mdo C. Partial recording protocols for periodontal disease assessment in epidemiological surveys. Cad Saude Publica. 2007; 23:33-42. [PubMed: 17187102]

4. Kingman A, Albandar JM. Methodological aspects of epidemiological studies of periodontal diseases. Periodontol 2000. 2002; 29:11-30. [PubMed: 12102701]

5. Ramfjord SP. Indices for prevalence and incidence of periodontal disease. J Periodontol. 1959; 30:51-59.

6. Ainamo J, Barmes D, Beagrie G, Cutress T, Martin J, Sardo-Infirri J. Development of the World Health Organization (WHO) community periodontal index of treatment needs (CPITN). Int Dent J. 1982; 32:281-291. [PubMed: 6958657]

7. National Center for Health Statistics, Centers for Disease Control and Prevention. Plan and Operation of the Third National Health and Nutrition Examination Survey, 1988-94 (NHANES III). Vital Health Stat. 1994; 32:1-2.

8. Eke PI, Thornton-Evans GO, Wei L, Borgnakke WS, Dye BA. Accuracy of NHANES periodontal examination protocols. J Dent Res. 2010; 89:1208-1213. [PubMed: 20858782]

9. Albandar JM. Underestimation of periodontitis in NHANES surveys. J Periodontol. 2011; 82:337341. [PubMed: 21214340]

10. Thomson WM, Williams SM. Partial- or full-mouth approaches to assessing the prevalence of and risk factors for periodontal disease in young adults. J Periodontol. 2002; 73:1010-1014. [PubMed: 12296585]

11. Fletcher, RH.; Fletcher, SW.; Wagner, EH. Clinical Epidemiology: The essential. 3rd ed. Artes Médicas; Porto Alegre: 1996. p. 57-68.In Portuguese

12. Albandar JM. Periodontal diseases in North America. Periodontol 2000. 2002; 29:31-69. [PubMed: 12102702]

13. Sheiham A, Netuveli GS. Periodontal diseases in Europe. Periodontol 2000. 2002; 29:104-121. [PubMed: 12102705]

14. Gjermo P, Rösing CK, Susin C, Oppermann R. Periodontal diseases in Central and South America. Periodontol 2000. 2002; 29:70-78. [PubMed: 12102703]

15. Baelum V, Scheutz F. Periodontal diseases in Africa. Periodontol 2000. 2002; 29:79-103.

[PubMed: 12102704] 
16. Instituto Brasileiro de Geografia e Estatística (IBGE). [Accessed February 15, 2011] Brazilian Census. 2010. Available from: http://www.ibge.gov.br

17. Barros FC, Victora CG, Horta BL, Gigante DP. Methodology of the Pelotas birth cohort study from 1982 to 2004-5, Southern Brazil. Rev Saude Publica. 2008; 42(Suppl. 2):7-15. In Portuguese. [PubMed: 19142340]

18. Peres MA, Thomson WM, Peres KG, et al. Challenges in comparing the methods and findings of cohort studies of oral health: The Dunedin (New Zealand) and Pelotas (Brazil) studies. Aust N Z J Public Health. 2011; 35:549-556. [PubMed: 22151162]

19. Peres MA, Barros AJ, Peres KG, et al. Oral health follow-up studies in the 1993 Pelotas (Brazil) birth cohort study: Methodology and principal results. Cad Saude Publica. 2010; 26:1990-1999. [PubMed: 20963297]

20. Cortes MI, Marcenes W, Sheiham A. Impact of traumatic injuries to the permanent teeth on the oral health-related quality of life in 12-14-year-old children. Community Dent Oral Epidemiol. 2002; 30:193-198. [PubMed: 12000342]

21. World Health Organization. Oral Health Surveys: Basic Methods. World Health Organization; Geneva: 1997. p. 35-44.

22. O’Brien, M. Report of Dental Survey, Office of Population Censuses and Surveys. Her Majesty's Stationery Office; London: 1994. Children's Dental Health in the United Kingdom 1993; p. 109

23. Barros AJ, Hirakata VN. Alternatives for logistic regression in cross-sectional studies: An empirical comparison of models that directly estimate the prevalence ratio. BMC Med Res Methodol. 2003; 3:21. [PubMed: 14567763]

24. Szklo, M.; Javier Nieto, F. Epidemiology: Beyond the Basics. Jones and Bartlett Publishers; Sudbury, MA: 2004. p. 309

25. Marthaler TM. A standardized system of recording dental conditions. Helv Odontol Acta. 1966; 10:1-18. [PubMed: 4379484]

26. Berman DS, Slack GL. Dental caries in English school children: A longitudinal study. Br Dent J. 1972; 133:529-538. [PubMed: 4144217]

27. McDonald SP, Sheiham A. The distribution of caries on different tooth surfaces at varying levels of caries - a compilation of data from 18 previous studies. Community Dent Health. 1992; 9:3948. [PubMed: 1535537]

28. Batchelor PA, Sheiham A. Grouping of tooth surfaces by susceptibility to caries: A study in 5-16 year-old children. BMC Oral Health. 2004; 4:2. [PubMed: 15511295] 
Table 1

Sample Characteristics at 12 and 24 Years Old, 1982 and 1993 Pelotas Birth Cohort Studies, Brazil

\begin{tabular}{|c|c|c|c|c|}
\hline \multirow[b]{2}{*}{ Variables } & \multicolumn{2}{|c|}{12 Years Old } & \multicolumn{2}{|r|}{24 Years Old } \\
\hline & $\mathbf{n}$ & $\%(95 \% \mathrm{CI})$ & $\mathbf{n}$ & $\%(95 \% \mathrm{CI})$ \\
\hline \multicolumn{5}{|l|}{ Sex } \\
\hline Males & 182 & $53.7(48.4 ; 59.0)$ & 375 & $52.8(49.1 ; 56.5)$ \\
\hline Females & 157 & $46.3(41.0 ; 51.6)$ & 335 & $47.2(43.4 ; 50.9)$ \\
\hline \multicolumn{5}{|l|}{ Skin color } \\
\hline White & 265 & $78.2(73.8 ; 82.6)$ & 505 & $71.2(67.7 ; 74.5)$ \\
\hline Dark-skinned blacks & 49 & $14.4(10.7 ; 18.2)$ & 75 & $10.6(8.4 ; 13.1)$ \\
\hline Light-skinned blacks & 25 & $7.4(4.6 ; 10.2)$ & 129 & $18.2(15.4 ; 21.2)$ \\
\hline \multicolumn{5}{|l|}{ Mother's schooling (years) } \\
\hline$\leq 4$ & 96 & $28.3(23.5 ; 33.1)$ & 229 & $32.3(28.9 ; 35.9)$ \\
\hline 5 to 8 & 165 & $48.7(43.3 ; 54.0)$ & 318 & $44.9(41.2 ; 48.7)$ \\
\hline 9 to 11 & 56 & $16.5(12.5 ; 20.5)$ & 74 & $10.5(8.3 ; 12.9)$ \\
\hline$\geq 12$ & 22 & $6.5(3.9 ; 9.1)$ & 87 & $12.3(10.0 ; 14.9)$ \\
\hline \multicolumn{5}{|c|}{ Family income per month (BMW) ${ }^{*}$} \\
\hline$\unlhd$ & 61 & $18.0(13,9 ; 22,1)$ & 63 & $9.1(7.0 ; 11.4)$ \\
\hline 1.1 to 3 & 150 & $44.2(38,9 ; 49,6)$ & 283 & $40.7(37.0 ; 44.4)$ \\
\hline$\geq 3.1$ & 128 & $37.8(32,6 ; 42,9)$ & 350 & $50.2(46.4 ; 53.9)$ \\
\hline \multicolumn{5}{|l|}{ Daily toothbrushing } \\
\hline Yes & 329 & $97.3(95.6 ; 99.1)$ & 711 & $98.7(97.6 ; 99.4)$ \\
\hline No & 9 & $2.7(0.9 ; 4.4)$ & 9 & $1.3(0.6 ; 2.4)$ \\
\hline \multicolumn{5}{|c|}{ Dental visit in the past year } \\
\hline Yes & 156 & $35.0(28.9 ; 41.1)$ & 384 & $55.6(51.8 ; 59.3)$ \\
\hline No & 84 & $65.0(58.9 ; 71.1)$ & 307 & $44.4(40.6 ; 48.2)$ \\
\hline \multicolumn{5}{|l|}{ Current Smoker } \\
\hline Yes & & & 537 & $22.8(19.8 ; 26.1)$ \\
\hline No & & & 159 & $77.2(73.8 ; 80.2)$ \\
\hline
\end{tabular}

For BMW, R\$ 300.00 in $2005(\mathrm{R} \$ 2.50=\mathrm{US} \$ 1.00)$ and $\mathrm{R} \$ 350.00$ in $2006(\mathrm{R} \$ 2.20=\mathrm{US} \$ 1.00)$. 
Table 2

Prevalence of Periodontal Diseases at Ages 12 and 24 Years According to Different Protocols, 1982 and 1993 Pelotas Birth Cohorts, Brazil

\begin{tabular}{|c|c|c|c|c|c|c|c|c|}
\hline \multirow[b]{3}{*}{ Protocols } & \multicolumn{8}{|c|}{ Prevalence of Periodontal Outcomes } \\
\hline & \multicolumn{2}{|c|}{$\begin{array}{l}\text { Gingival BOP at } \\
\text { Age 12 Years } \\
(\mathbf{n}=339)\end{array}$} & \multicolumn{2}{|c|}{$\begin{array}{c}\text { Gingival BOP at } \\
\text { Age 24 Years } \\
(n=720)\end{array}$} & \multicolumn{2}{|c|}{$\begin{array}{c}\text { Dental Calculus at } \\
\text { Age 24 Years } \\
(\mathbf{n}=\mathbf{7 2 0})\end{array}$} & \multicolumn{2}{|c|}{$\begin{array}{l}\text { Periodontal Pocket at } \\
\text { Age 24 Years } \\
(n=720)\end{array}$} \\
\hline & $\mathbf{n}$ & $\%(95 \% \mathrm{CI})$ & $\mathbf{n}$ & $\%(95 \% \mathrm{CI})$ & $\mathbf{n}$ & $\%(95 \% \mathrm{CI})$ & $\mathbf{n}$ & $\%(95 \% \mathbf{C I})$ \\
\hline FM & 298 & $87.9(84.4 ; 91.4)$ & 270 & $37.5(33.9 ; 41.1)$ & 629 & $87.4(84.7 ; 89.7)$ & 24 & $3.3(2.1 ; 4.9)$ \\
\hline RT & 243 & $71.7(66.8 ; 76.5)$ & 153 & $21.2(18.3 ; 24.4)$ & 583 & $81.0(77.9 ; 83.8)$ & 7 & $1.0(0.4 ; 2.0)$ \\
\hline CPI & 250 & $73.7(69.0 ; 78.5)$ & 202 & $28.1(24.8 ; 31.5)$ & 620 & $86.1(83.4 ; 88.5)$ & 16 & $2.2(1.3 ; 3.6)$ \\
\hline Half-mouth quadrants 1 and 3 & 270 & $79.6(75.3 ; 84.0)$ & 204 & $28.3(25.1 ; 31.8)$ & 609 & $84.6(81.7 ; 87.1)$ & 17 & $2.4(1.4 ; 3.7)$ \\
\hline Half-mouth quadrants 2 and 4 & 273 & $80.5(76.3 ; 84.8)$ & 215 & $29.9(26.5 ; 33.3)$ & 608 & $84.4(81.6 ; 87.0)$ & 14 & $1.9(1.1 ; 3.2)$ \\
\hline
\end{tabular}


Table 3

Estimates of Sensitivity, Absolute and Relative Bias, and Inflation Factor of Different Protocols Compared to FM at Ages 12 and 24 Years, Pelotas 1982 and 1993 Birth Cohorts, Brazil

\begin{tabular}{|c|c|c|c|c|}
\hline $\begin{array}{l}\text { Periodontal Diseases Assessed by } \\
\text { Different Protocols }\end{array}$ & $\begin{array}{c}\mathrm{SE} \\
(95 \% \mathrm{CI})^{*}\end{array}$ & $\begin{array}{c}\text { Absolute } \\
\text { Bias }^{\dagger}\end{array}$ & $\begin{array}{c}\text { Relative } \\
\text { Bias }^{*}\end{array}$ & $\begin{array}{l}\text { Inflation } \\
\text { Factor }^{\S}\end{array}$ \\
\hline \multicolumn{5}{|l|}{ GingivalBOP at age 12 years } \\
\hline $\mathrm{RT}(\mathrm{n}=243)$ & $81.5(76.7 ; 85.8)$ & -16.2 & 18.4 & 1.23 \\
\hline CPI $(n=250)$ & $83.9(79.2 ; 87.9)$ & -14.4 & 16.2 & 1.19 \\
\hline Half-mouth quadrants 1 and $3(n=270)$ & $90.6(86.7 ; 93.7)$ & -8.3 & 9.4 & 1.10 \\
\hline Half-mouth quadrants 2 and $4(n=273)$ & $91.6(87.9 ; 94.5)$ & -7.4 & 8.4 & 1.09 \\
\hline \multicolumn{5}{|l|}{ Gingival BOP at age 24 years } \\
\hline $\mathrm{RT}(\mathrm{n}=153)$ & $56.7(50.5 ; 62.7)$ & -16.3 & 43.5 & 1.77 \\
\hline CPI $(n=202)$ & $74.8(69.2 ; 79.9)$ & -9.4 & 25.1 & 1.33 \\
\hline Half-mouth quadrants 1 and $3(n=204)$ & $75.6(70.0 ; 80.6)$ & -9.2 & 24.5 & 1.32 \\
\hline Half-mouth quadrants 2 and $4(n=215)$ & $79.6(74.3 ; 84.3)$ & -7.6 & 20.3 & 1.25 \\
\hline \multicolumn{5}{|l|}{ Dental calculus at age 24 years } \\
\hline $\mathrm{RT}(\mathrm{n}=583)$ & $92.7(90.4 ; 94.6)$ & -6.4 & 7.3 & 1.08 \\
\hline $\mathrm{CPI}(\mathrm{n}=620)$ & $98.6(97.3 ; 99.3)$ & -1.3 & 1.5 & 1.02 \\
\hline Half-mouth quadrants 1 and $3(n=609)$ & $96.8(95.1 ; 98.0)$ & -2.8 & 3.2 & 1.03 \\
\hline Half-mouth quadrants 2 and $4(n=608)$ & $96.7(94.9 ; 97.9)$ & -3.0 & 3.4 & 1.03 \\
\hline \multicolumn{5}{|l|}{ Periodontal pocket at age 24 years } \\
\hline $\mathrm{RT}(\mathrm{n}=7)$ & $29.2(12.6 ; 51.1)$ & -2.3 & 69.7 & 3.30 \\
\hline $\mathrm{CPI}(\mathrm{n}=16)$ & $66.7(44.7 ; 84.4)$ & -1.1 & 33.3 & 1.50 \\
\hline Half-mouth quadrants 1 and $3(n=17)$ & $70.8(48.9 ; 87.4)$ & -0.9 & 27.3 & 1.38 \\
\hline Half-mouth quadrants 2 and $4(n=14)$ & $58.3(36.6 ; 77.9)$ & -1.4 & 42.4 & 1.74 \\
\hline
\end{tabular}

Sensitivity $(\mathrm{SE})=($ prevalence in the tested protocols/prevalence in the gold-standard FM $) \times 100$.

${ }^{\dagger}$ Absolute bias $=$ absolute difference between prevalence $=$ prevalence in the tested protocols minus prevalence in the gold-standard FM.

${ }^{*}$ Relative bias $=$ percentage of true prevalence underestimation $=($ absolute difference in the prevalence/prevalence in the gold-standard FM $) \times 100$.

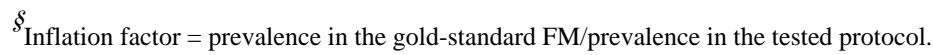




\section{Table 4}

PRs (95\% CI) of Gingival Bleeding for Independent Variables and Different Protocols at Ages 12 and 24 Years in Patients From Pelotas Birth Cohorts, Brazil

\begin{tabular}{|c|c|c|c|c|c|}
\hline \multirow[b]{2}{*}{ Variables } & \multicolumn{5}{|c|}{ Protocols } \\
\hline & $\mathbf{F M}$ & RT & CPI & HM-1/3 & HM-2/4 \\
\hline \multicolumn{6}{|l|}{ Sex } \\
\hline Male & 1.00 & 1.00 & 1.00 & 1.00 & 1.00 \\
\hline Female (12) & $0.98(0.91 ; 1.07)$ & $0.91(0.80 ; 1.05)$ & $0.93(0.81 ; 1.05)$ & $1.01(0.91 ; 1.13)$ & $0.95(0.85 ; 1.06)$ \\
\hline Female (24) & $0.98(0.81 ; 1.19)$ & $1.03(0.78 ; 1.37)$ & $1.10(0.87 ; 1.39)$ & $1.01(0.80 ; 1.28)$ & $0.93(0.74 ; 1.16)$ \\
\hline \multicolumn{6}{|l|}{ Skin Color } \\
\hline White & 1.00 & 1.00 & 1.00 & 1.00 & 1.00 \\
\hline Light-skinned black (12) & $1.00(0.86 ; 1.17)$ & $0.96(0.73 ; 1.27)$ & $1.00(0.77 ; 1.29)$ & $1.01(0.82 ; 1.24)$ & $1.00(0.82 ; 1.23)$ \\
\hline Dark-skinned black (12) & $1.03(0.92 ; 1.14)$ & $1.13(0.96 ; 1.33)$ & $1.16(1.00 ; 1.34)$ & $1.03(0.89 ; 1.19)$ & $1.08(0.95 ; 1.13)$ \\
\hline Light-skinned black (24) & $1.17(0.92 ; 1.48)$ & $1.29(0.92 ; 1.82)$ & $1.13(0.84 ; 1.52)$ & $1.22(0.91 ; 1.62)$ & $1.30(1.00 ; 1.70)$ \\
\hline Dark-skinned black (24) & $1.19(0.89 ; 1.59)$ & $1.14(0.73 ; 1.80)$ & $1.07(0.73 ; 1.57)$ & $1.25(0.88 ; 1.77)$ & $1.15(0.80 ; 1.64$ \\
\hline \multicolumn{6}{|l|}{ Mother's schooling (years) } \\
\hline$\leq 4$ & 1.00 & 1.00 & 1.00 & 1.00 & 1.00 \\
\hline 5 to $8(12)$ & $1.01(0.93 ; 1.11)$ & $1.02(0.88 ; 1.17)$ & $1.03(0.89 ; 1.18)$ & $1.02(0.91 ; 1.14)$ & $1.02(0.91 ; 1.14)$ \\
\hline 9 to $11(12)$ & $0.99(0.87 ; 1.12)$ & $0.81(0.63 ; 1.03)$ & $0.90(0.73 ; 1.12)$ & $0.89(0.74 ; 1.07)$ & $0.86(0.71 ; 1.03)$ \\
\hline$\geq 12(12)$ & $0.82(0.63 ; 1.07)$ & $0.67(0.43 ; 1.03)$ & $0.79(0.55 ; 1.14)$ & $0.66(0.45 ; 0.98)$ & $0.71(0.49 ; 1.02)$ \\
\hline 5 to $8(24)$ & $0.81(0.65 ; 0.99)$ & $0.85(0.62 ; 1.17)$ & $0.82(0.63 ; 1.06)$ & $0.86(0.66 ; 1.12)$ & $0.75(0.59 ; 0.97)$ \\
\hline 9 to $11(24)$ & $1.00(0.74 ; 1.35)$ & $1.03(0.65 ; 1.64)$ & $0.91(0.61 ; 1.35)$ & $0.99(0.67 ; 1.46)$ & $0.93(0.65 ; 1.34)$ \\
\hline$\geq 12(24)$ & $0.66(0.46 ; 0.95)$ & $0.68(0.40 ; 1.16)$ & $0.63(0.40 ; 0.99)$ & $0.77(0.50 ; 1.17)$ & $0.54(0.34 ; 0.85$ \\
\hline \multicolumn{6}{|c|}{ Family income per month (BMW) ${ }^{*}$} \\
\hline 4 & 1.00 & 1.00 & 1.00 & 1.00 & 1.00 \\
\hline 1.1 to $3(12)$ & $1.00(0.90 ; 1.11)$ & $0.98(0.83 ; 1.17)$ & $1.08(0.91 ; 1.29)$ & $1.05(0.90 ; 1.22)$ & $1.00(0.88 ; 1.15)$ \\
\hline$\geq 3.1(12)$ & $0.98(0.87 ; 1.10)$ & $0.89(0.74 ; 1.08)$ & $0.96(0.79 ; 1.17)$ & $0.97(0.83 ; 1.14)$ & $0.90(0.77 ; 1.04)$ \\
\hline 1.1 to $3(24)$ & $0.82(0.61 ; 1.11)$ & $0.57(0.38 ; 0.85)$ & $0.86(0.59 ; 1.26)$ & $0.83(0.57 ; 1.21)$ & $0.74(0.53 ; 1.05)$ \\
\hline $23.1(24)$ & $0.70(0.52 ; 0.95)$ & $0.49(0.33 ; 0.73)$ & $0.73(0.50 ; 1.07)$ & $0.68(0.47 ; 0.99)$ & $0.63(0.45 ; 0.89)$ \\
\hline \multicolumn{6}{|l|}{ Daily toothbrushing } \\
\hline No & 1.00 & 1.00 & 1.00 & 1.00 & 1.00 \\
\hline Yes (12) & $0.88(0.84 ; 0.91)$ & $0.92(0.65 ; 1.32)$ & $1.11(0.70 ; 1.77)$ & $0.79(0.75 ; 0.84)$ & $0.80(0.76 ; 0.85)$ \\
\hline Yes (24) & $0.55(0.34 ; 0.89)$ & $0.31(0.19 ; 0.50)$ & $0.50(0.27 ; 0.91)$ & $0.50(0.28 ; 0.91)$ & $0.44(0.27 ; 0.71)$ \\
\hline \multicolumn{6}{|l|}{ Dental visit in the last year } \\
\hline No & 1.00 & 1.00 & 1.00 & 1.00 & 1.00 \\
\hline Yes (12) & $1.01(0.91 ; 1.12)$ & $0.99(0.83 ; 1.19)$ & $1.02(0.86 ; 1.22)$ & $1.02(0.87 ; 1.18)$ & $0.88(0.77 ; 1.01)$ \\
\hline Yes (24) & $0.76(0.62 ; 0.92)$ & $0.58(0.43 ; 0.78)$ & $0.74(0.58 ; 0.94)$ & $0.69(0.54 ; 0.88)$ & $0.69(0.54 ; 0.87)$ \\
\hline \multicolumn{6}{|l|}{ Current smoker } \\
\hline No & 1.00 & 1.00 & 1.00 & 1.00 & 1.00 \\
\hline \multicolumn{6}{|l|}{ Yes (12) } \\
\hline Yes (24) & $1.02(0.81 ; 1.29)$ & $1.07(0.77 ; 1.51)$ & $1.28(0.99 ; 1.66)$ & $1.00(0.76 ; 1.33)$ & $1.13(0.87 ; 1.46)$ \\
\hline
\end{tabular}

$\mathrm{CPI}=\mathrm{CPITN}$, which is community periodontal index of treatment needs; HM-1/3 = half-mouth quadrants 1 and $3 ; \mathrm{HM}-2 / 4=$ half-mouth quadrants 2 and $4 ;(12)=$ at age $12 ;(24)=$ at age 24 . 
Family income in BMW = 1 BMW was US $\$ 200.00$ in 2006. 
Table 5

PRs (95\% CI) of Dental Calculus (C) and PD for Independent Variables and Different Protocols at Age 24 Years in Patients From Pelotas Birth Cohorts, Brazil

\begin{tabular}{|c|c|c|c|c|c|}
\hline \multirow[b]{2}{*}{ Variables } & \multicolumn{5}{|c|}{ Protocols } \\
\hline & FM & RT & CPI & HM-1/3 & HM-2/4 \\
\hline \multicolumn{6}{|l|}{ Sex } \\
\hline Male & 1.00 & 1.00 & 1.00 & 1.00 & 1.00 \\
\hline Female (C) & $0.97(0.92 ; 1.02)$ & $0.95(0.88 ; 1.02)$ & $0.97(0.9 ; 1.03)$ & $0.95(0.89 ; 1.01)$ & $0.96(0.90 ; 1.02)$ \\
\hline Female (PD) & $1.34(0.59 ; 3.07)$ & $0.83(0.19 ; 3.72)$ & $1.44(0.54 ; 3.82)$ & $1.12(0.42 ; 2.95)$ & $1.12(0.36 ; 3.44)$ \\
\hline \multicolumn{6}{|l|}{ Skin color } \\
\hline White & 1.00 & 1.00 & 1.00 & 1.00 & 1.00 \\
\hline Light-skinned black (C) & $1.07(1.00 ; 1.14)$ & $1.10(1.02 ; 1.19)$ & $1.08(1.00 ; 1.15)$ & $1.08(1.00 ; 1.15)$ & $1.07(0.99 ; 1.14)$ \\
\hline Dark-skinned black (C) & $1.00(0.91 ; 1.10)$ & $1.02(0.91 ; 1.15)$ & $1.00(0.91 ; 1.11)$ & $1.00(0.91 ; 1.12)$ & $1.02(0.92 ; 1.13)$ \\
\hline Light-skinned black (PD) & $1.56(0.62 ; 3.96)$ & $5.21(1.18 ; 23.05)$ & $1.96(0.68 ; 5.63)$ & $1.96(0.68 ; 5.63)$ & $2.24(0.66 ; 7.53)$ \\
\hline Dark-skinned black (PD) & $0.45(0.06 ; 3.35)$ & - & $0.67(0.09 ; 5.19)$ & $0.67(0.09 ; 5.19)$ & $0.96(0.12 ; 7.72)$ \\
\hline \multicolumn{6}{|l|}{ Mother's schooling (yrs) } \\
\hline$\leq 4$ & 1.00 & 1.00 & 1.00 & 1.00 & 1.00 \\
\hline 5 to $8(C)$ & $1.02(0.95 ; 1.07)$ & $0.98(0.90 ; 1.07)$ & $1.00(0.93 ; 1.07)$ & $0.99(0.92 ; 1.06)$ & $1.02(0.95 ; 1.09)$ \\
\hline 9 to $11(\mathrm{C})$ & $1.07(0.99 ; 1.15)$ & $1.08(0.97 ; 1.19)$ & $1.06(0.98 ; 1.15)$ & $1.08(0.99 ; 1.18)$ & $1.10(1.00 ; 1.20)$ \\
\hline$\geq 12(\mathrm{C})$ & $0.92(0.82 ; 1.93)$ & $0.96(0.84 ; 1.09)$ & $0.93(0.83 ; 1.04)$ & $0.93(0.83 ; 1.05)$ & $0.96(0.85 ; 1.08)$ \\
\hline 5 to $8(\mathrm{PD})$ & $0.26(0.08 ; 0.81)$ & - & $0.36(0.10 ; 1.18)$ & $0.16(0.03 ; 0.73)$ & $0.58(0.16 ; 2.12)$ \\
\hline 9 to $11(\mathrm{PD})$ & $1.12(0.37 ; 3.43)$ & $0.77(0.08 ; 6.82)$ & $1.16(0.32 ; 4.26)$ & $1.03(0.29 ; 3.71)$ & $1.24(0.24 ; 6.25)$ \\
\hline$\geq 12$ (PD) & $0.72(0.20 ; 2.51)$ & $1.31(0.25 ; 7.06)$ & $0.33(0.04 ; 2.59)$ & $0.58(0.13 ; 2.66)$ & $0.53(0.06 ; 4.44$ \\
\hline \multicolumn{6}{|c|}{ Family income per month (BMW) ${ }^{*}$} \\
\hline 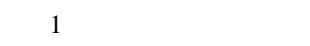 & 1.00 & 1.00 & 1.00 & 1.00 & 1.00 \\
\hline 1.1 to $3(\mathrm{C})$ & $1.00(0.91 ; 1.10)$ & $0.96(0.86 ; 1.09)$ & $0.97(0.89 ; 1.08)$ & $1.01(0.90 ; 1.13)$ & $1.01(0.90 ; 1.13)$ \\
\hline $23.1(\mathrm{C})$ & $0.96(0.87 ; 1.06)$ & $0.95(0.84 ; 1.07)$ & $0.95(0.87 ; 1.05)$ & $0.96(0.86 ; 1.08)$ & $1.00(0.89 ; 1.12)$ \\
\hline 1.1 to $3(\mathrm{PD})$ & $0.31(0.12 ; 0.80)$ & - & $0.26(0.08 ; 0.85)$ & $0.45(0.14 ; 1.43)$ & $0.39(0.12 ; 1.29)$ \\
\hline $23.1(\mathrm{PD})$ & $0.18(0.06 ; 0.49)$ & - & $0.18(0.05 ; 0.60)$ & $0.23(0.06 ; 0.82)$ & $0.14(0.03 ; 0.59)$ \\
\hline \multicolumn{6}{|l|}{ Daily toothbrushing } \\
\hline No & 1.00 & 1.00 & 1.00 & 1.00 & 1.00 \\
\hline Yes $(C)$ & $0.98(0.78 ; 1.24)$ & $1.04(0.73 ; 1.48)$ & $0.97(0.77 ; 1.22)$ & $0.95(0.75 ; 1.20)$ & $0.95(0.75 ; 1.20)$ \\
\hline Yes (PD) & $0.29(0.04 ; 1.93)$ & - & - & - & $0.16(0.02 ; 1.26)$ \\
\hline \multicolumn{6}{|l|}{ Dental visit in the last year } \\
\hline No & 1.00 & 1.00 & 1.00 & 1.00 & 1.00 \\
\hline Yes (C) & $0.93(0.88 ; 0.99)$ & $0.90(0.84 ; 0.97)$ & $0.92(0.87 ; 0.98)$ & $0.94(0.88 ; 1.00)$ & $0.89(0.84 ; 0.95)$ \\
\hline Yes (PD) & $0.57(0.26 ; 1.27)$ & $0.60(0.14 ; 2.66)$ & $0.36(0.13 ; 1.04)$ & $0.71(0.28 ; 1.82)$ & $0.44(1.15 ; 1.31)$ \\
\hline \multicolumn{6}{|l|}{ Current smoker } \\
\hline No & 1.00 & 1.00 & 1.00 & 1.00 & 1.00 \\
\hline Yes (C) & $1.10(1.04 ; 1.16)$ & $1.15(1.07 ; 1.23)$ & $1.11(1.05 ; 1.17)$ & $1.14(1.07 ; 1.20)$ & $1.13(1.06 ; 1.20)$ \\
\hline Yes (PD) & $0.89(0.34 ; 2.34)$ & $0.56(0.07 ; 4.64)$ & $0.48(0.11 ; 2.10)$ & $1.04(0.34 ; 3.14)$ & $0.92(0.26 ; 3.26)$ \\
\hline
\end{tabular}

$\mathrm{CPI}=\mathrm{CPITN}$, which is community periodontal index of treatment needs; HM-1/3 = half-mouth quadrants 1 and $3 ; \mathrm{HM}-2 / 4=$ half-mouth quadrants 2 and $4 ; C=$ dental calculus; $\mathrm{PD}=$ probing depth $\geq 4 \mathrm{~mm} ;-=$ insufficient number of patients for data analyses. 
Family income in BMW = 1 BMW was US $\$ 200.00$ in 2006. 